Arq. Bras. Med. Vet. Zootec., v.69, n.5, p.1225-1230, 2017

\title{
Mieloma múltiplo em cão com apresentação clínica atípica de paralisia facial bilateral: relato de caso
}

\author{
[Multiple Myeloma in dog with atypical clinical presentation of
}

bilateral facial paralysis: case report]

\section{R.S. Santos ${ }^{1}$, C.C. Luz $^{2}$, V.M. Rocha ${ }^{2}$, D.F. Larangeira ${ }^{2,3}$, S.M. Barrouin-Melo ${ }^{2,3 *}$}

${ }^{1}$ Residência - Universidade Federal da Bahia - UFBA - Salvador, BA

${ }^{2}$ Hospital de Medicina Veterinária - Universidade Federal da Bahia - UFBA - Salvador, BA

${ }^{3}$ Escola de Medicina Veterinária e Zootecnia - Universidade Federal da Bahia - UFBA - Salvador, BA

\section{RESUMO}

Objetivou-se com o presente trabalho relatar um caso de mieloma múltiplo (MM) em uma cadela com apresentação clínica atípica de rigidez da musculatura facial. Foram realizados hemogramas seriados, exames bioquímicos, sumário de urina, sorologia para leishmaniose, radiografias de crânio, citologia de medula óssea e eletroforese de proteínas séricas. O infiltrado plasmocitário em medula óssea $>20 \%$, a gamopatia monoclonal e as lesões compatíveis com lise óssea, observados no mielograma, eletroforese de proteínas e exame radiográfico, respectivamente, foram determinantes para conclusão diagnóstica de MM. A doença pode ter uma apresentação clínica variável em cães e representar um desafio ao diagnóstico na clínica de animais de companhia, principalmente em áreas endêmicas de doenças infecciosas que se manifestam com apresentações clínicas e laboratoriais semelhantes.

Palavras-chave: neoplasia, canino, apresentação atípica, diagnóstico diferencial

\begin{abstract}
This paper reports a case of multiple myeloma $(M M)$ in a bitch with atypical clinical presentation of rigidity of the facial muscles. Hemogram, biochemical tests, urinalysis, serology for leishmaniasis, skull radiography, bone marrow cytology and serum protein electrophoresis were performed. The plasma cell infiltration in bone marrow was $>20 \%$, the monoclonal gammopathy and lesions compatible with bone lysis observed in the myelogram, protein electrophoresis and radiographic examination respectively, were decisive for diagnostic conclusion of MM. The disease may have a variable clinical presentation in dogs and pose a challenge for diagnosis in the pet clinic, especially in endemic areas of infectious diseases that present with similar clinical and laboratory presentations.
\end{abstract}

Keywords: neoplasm, canine, atypical presentation, differential diagnosis

\section{INTRODUÇÃO}

O mieloma múltiplo (MM) representa menos de $1 \%$ dos tumores malignos em animais, abrangendo aproximadamente $8 \%$ dos tumores hematopoiéticos (Sternberg et al., 2009). A doença não apresenta predisposição sexual ou racial, sendo a faixa etária mais comumente acometida entre oito e nove anos (Geigy et al., 2012). A fisiopatologia do MM caracteriza-se por proliferação anormal de plasmócitos na

Recebido em 13 de fevereiro de 2015

Aceito em 24 de agosto de 2016

*Autor para correspondência (corresponding author)

E-mail: barrouin@ufba.br medula óssea (MO), com consequente produção e secreção de grande quantidade de imunoglobulina monoclonal integral ou em fragmentos, as chamadas proteínas $\mathrm{M}$ ou paraproteínas (Ruthanne Chun, 2005). Cães com MM podem apresentar letargia, hiporexia, distúrbios cardíacos, alterações neurológicas, insuficiência renal, retinopatias ou diátese hemorrágica como consequência da hiperviscosidade sanguínea associada à hiperproteinemia. Sinais indicativos de dor óssea decorrente de fraturas patológicas e intensa 
osteólise são comuns (Sternberg et al., 2009). Como os sinais clínicos apresentados geralmente são inespecíficos, relacionados à disfunção da MO devido à infiltração neoplásica e aos efeitos da alta concentração de proteína circulante, o MM torna-se uma doença de difícil diagnóstico. Tanto em seres humanos como em cães, a confirmação da suspeita clínica baseia-se na demonstração de pelo menos dois dos seguintes critérios: proliferação de células plasmocitarias atípicas na medula óssea $(>10 \%)$, ou plasmocitoma, gamopatia monoclonal, associado a lesões ósseas líticas e proteinúria de Bence-Jones, hipercalcemia e alteração função renal (Tripp et al., 2009). Outras condições patológicas que possam induzir gamopatias monoclonais em animais, como leucemia linfocítica crônica, linfoma de células B, plasmocitoma, macroglobulinemia primária, ou infecções crônicas, como erliquiose, leishmaniose, dirofilariose, devem ser consideradas como diagnóstico diferencial (Tripp et al., 2009; Geigy et al., 2012). O tratamento quimioterápico pode prolongar significativamente a sobrevida do paciente. No entanto, a cura é rara e recidivas são comuns, tornando o prognóstico reservado a desfavorável. As drogas mais utilizadas no tratamento de animais são agentes alquilantes, como o melfalano, combinado com a prednisona ou outros corticoides (Sternberg et al., 2009).

Objetivou-se, com o presente relato, descrever um caso de mieloma múltiplo em um cão, com uma apresentação clínica atípica de paralisia facial.

\section{CASUÍSTICA}

Uma cadela sem raça definida, com nove anos de idade, foi atendida no Hospital Veterinário da Universidade Federal da Bahia, apresentando rigidez da musculatura facial, apatia e hiporexia havia 15 dias. Foi relatado histórico de um episódio de epistaxe cerca de dois meses antes da consulta. Ao exame físico, o animal mostrou-se ativo, com bom estado corporal, mucosas discretamente hipocoradas, rigidez da musculatura facial com paralisia bilateral. Os demais parâmetros fisiológicos encontravam-se dentro da normalidade. Foram realizados hemograma e exames bioquímicos séricos, incluindo dosagens de ureia, creatinina, alanina aminotransferase (ALT), fosfatase alcalina (FA), cálcio, fósforo, proteínas totais, albumina, globulinas (Analisador hematológico veterinário pocH-100iV Diff, Sysmex® e bioquímico Doles D250, DOLES®), sorologia para leishmaniose e radiografias do crânio.

No hemograma, constatou-se pancitopenia com anemia normocítica, normocrômica, trombocitopenia, além de leucopenia (Tab. 1). Nos achados bioquímicos, foi observada hiperproteinemia devido à hiperglobulinemia com hipoalbuminemia e hipercalcemia. O sumário de urina e demais dosagens bioquímicas encontravam-se dentro dos valores da normalidade. A sorologia para leishmaniose revelou-se negativa. Ao exame radiográfico, foi diagnosticado um aumento localizado de radiotransparência na região dos seios nasais, sugestivo de lesão lítica. Não foram observados indícios de fraturas.

Por tratar-se de área endêmica para hemoparasitoses, a suspeita clínica inicial foi de erliquiose. Assim, iniciou-se o tratamento com doxiciclina $(6 \mathrm{mg} / \mathrm{kg})$, a cada 12 horas, por 28 dias.

O animal apresentou evolução com melhora inicial da anemia, entretanto houve persistência de leucopenia e trombocitopenia (Tab. 1). Hemogramas e exames bioquímicos séricos subsequentes revelaram decréscimo na contagem de eritrócitos e hiperglobulinemia persistente, respectivamente.

Diante da resposta pobre à terapêutica e às evidências hematológicas persistentes de resposta inflamatória crônica progressiva hiperproteinemia com hiperglobulinemia e hipoalbuminemia -, associada à disfunção medular - pancitopenia -, o plano diagnóstico foi reconduzido. Realizou-se um mielograma, que revelou a presença de um infiltrado plasmocitário maior que $20 \%$, sugerindo mieloma múltiplo (Fig. 1).

Realizou-se também uma eletroforese de proteínas séricas, que evidenciou um pico monoclonal em gamaglobulinas, bem como diminuição da fração referente à albumina $\mathrm{e}$ alfaglobulinas (Tab. 2 e Fig. 2). 
Mieloma múltiplo...

Tabela 1. Resultado dos hemogramas seriados e bioquímicos em cadela SRD com suspeita de mieloma múltiplo

\begin{tabular}{lccccc} 
& Dia 1 & Dia 28 & Dia 35 & Dia 48 & Valores de referência* \\
\hline Hemácia $\left(\times 10^{6} \mu / \mathrm{L}\right)$ & 5,5 & 6.62 & 4,47 & 3,44 & $5,5-8,5$ \\
Hemoglobina $(\mathrm{g} / \mathrm{dL})$ & 11,7 & 13,8 & 9,4 & 7,6 & $12-18$ \\
Volume globular $(\%)$ & 34,6 & 41,9 & 28,2 & 22,4 & $37-55$ \\
VGM (f/L) & 62,2 & 63,3 & 63,1 & 65,1 & $60-77$ \\
CHGM $(\%)$ & 33,8 & 32,9 & 33,3 & 33,9 & $32-36$ \\
Plaquetas $(/ \mu \mathrm{L})$ & 30.000 & 67.000 & 11.000 & 10.000 & $166.000-575.000$ \\
Leucócitos totais $(/ \mu \mathrm{L})$ & 5.800 & 4.200 & 3.700 & 2.700 & $6.000-17.000$ \\
Bastonetes $(/ \mu \mathrm{L})$ & 0 & 42 & 0 & 0 & $0-300$ \\
Segmentados $(/ \mu \mathrm{L})$ & 2.900 & 3.486 & 3293 & 2.349 & $3.000-11.500$ \\
Linfócitos $(/ \mu \mathrm{L})$ & 2.494 & 504 & 222 & 108 & $1.000-4.800$ \\
Monócitos $(/ \mu / \mathrm{L})$ & 116 & 42 & 74 & 81 & $150-1350$ \\
Eosinófilos $(/ \mu \mathrm{L})$ & 290 & 126 & 111 & 162 & $100-1.250$ \\
& & & & & \\
Proteína s. total $(\mathrm{g} / \mathrm{dL})$ & 11,8 & 7.6 & - & - & $5,4-7,1$ \\
Albumina $(\mathrm{g} / \mathrm{dL})$ & 2,0 & 2,4 & - & - & $2,6-3,3$ \\
Globulina $(\mathrm{g} / \mathrm{dL})$ & 9,8 & 5,2 & - & - & $2,7-4,4$ \\
Cálcio corrigido $(\mathrm{mg} / \mathrm{dL})$ & 11,5 & - & - & - & $9-11,3$ \\
Ureia $(\mathrm{mg} / \mathrm{dL})$ & 30 & - & - & - & $0,5-1,5$ \\
Creatinina $(\mathrm{mg} / \mathrm{dL})$ & 0,8 & - & - & - & $20-156$ \\
Fosfatase alcalina $(\mathrm{UI} / \mathrm{L})$ & 22 & - & - & - & $2,6-6,2$ \\
Fósforo $(\mathrm{mg} / \mathrm{dL})$ & 4 & - & - & - & \\
\hline
\end{tabular}

*Laboratório de análises clínicas (LAC) - Hospital de Medicina Veterinária - UFBA.

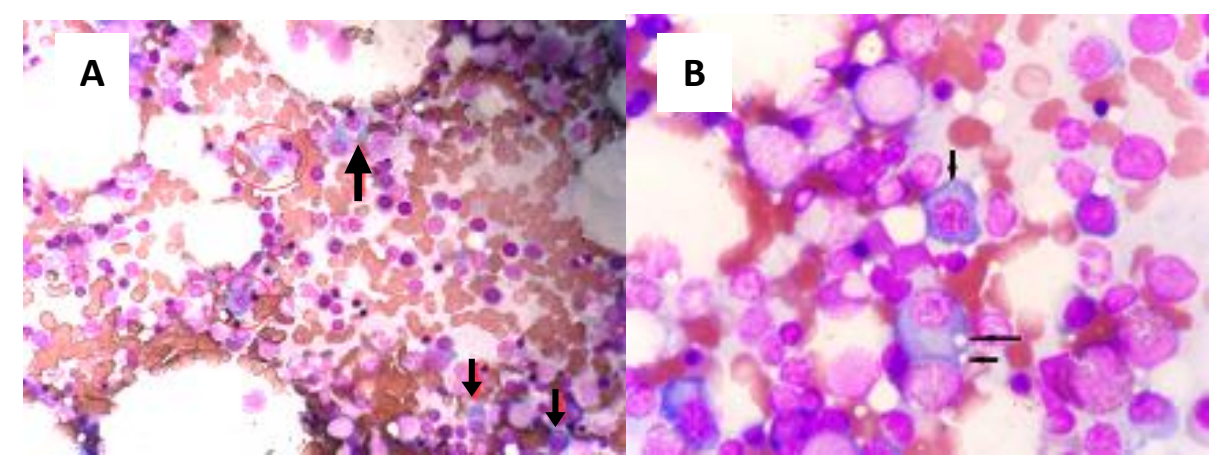

Figura 1. Imagens do mielograma de cadela, SRD com suspeita de MM, revelando presença de moderado infiltrado plasmocitário (setas). (A) obj. 40x, corante rápido (Panótico - RENYLAB ${ }^{\circledR}$ ); (B) obj. 100x, corante rápido $\left(\right.$ Panótico - RENYLAB ${ }^{\circledR}$ ). Fonte: Laboratório de Análises Clínicas (LAC) - Hospital de Medicina Veterinária - UFBA.

Tabela 2. Resultado da eletroforese de proteínas séricas em cadela SRD com suspeita de mieloma múltiplo. Aumento da concentração de gamaglobulinas, originando o pico monoclonal

\begin{tabular}{lcc}
\hline & $\begin{array}{c}\text { Valores } \\
\text { encontrados } \\
\mathrm{g} / \mathrm{dL}\end{array}$ & $\begin{array}{c}\text { Valores de } \\
\text { referência } \\
\mathrm{g} / \mathrm{dL} *\end{array}$ \\
\hline Albumina & 3,06 & $3,57-5,48$ \\
Alfa 1 & 0,10 & $0,18-0,40$ \\
Alfa 2 & 0,27 & $0,45-97$ \\
Beta 1 & 0,91 & $0,30-0,59$ \\
Beta 2 & 0,98 & $0,20-0,53$ \\
Gama & 2,28 & $0,71-1,56$ \\
\hline *Laboratório de Análises Clínicas (LAC) - Hospital
\end{tabular}

*Laboratório de Análises Clínicas (LAC) - Hospital de Medicina Veterinária - UFBA.
Os aspectos clínicos e laboratoriais, associados aos achados anteriores de lesão lítica em crânio, permitiram a conclusão do diagnóstico de mieloma múltiplo.

No último retorno, o animal apresentava-se apático e com presença de petéquias e sufusões disseminadas pela pele (Fig. 3). Realizou-se uma transfusão de sangue total para minimizar o quadro anêmico da cadela e, assim, proceder ao início da quimioterapia antineoplásica. No entanto, a guardiã não conseguiu arcar com os custos, e o quadro evoluiu para óbito. Não houve permissão para a realização da necropsia. 


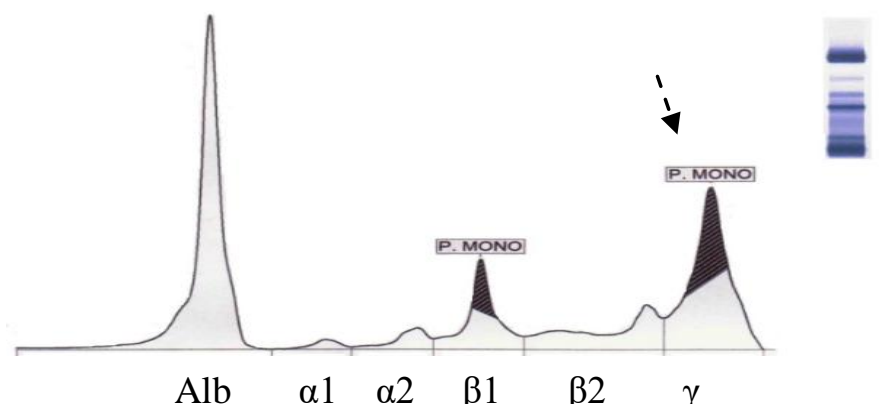

Figura 2. Resultado da eletroforese de proteínas séricas de uma cadela, SRD, com suspeita de mieloma múltiplo. Pico monoclonal na fração gama (seta pontilhada).

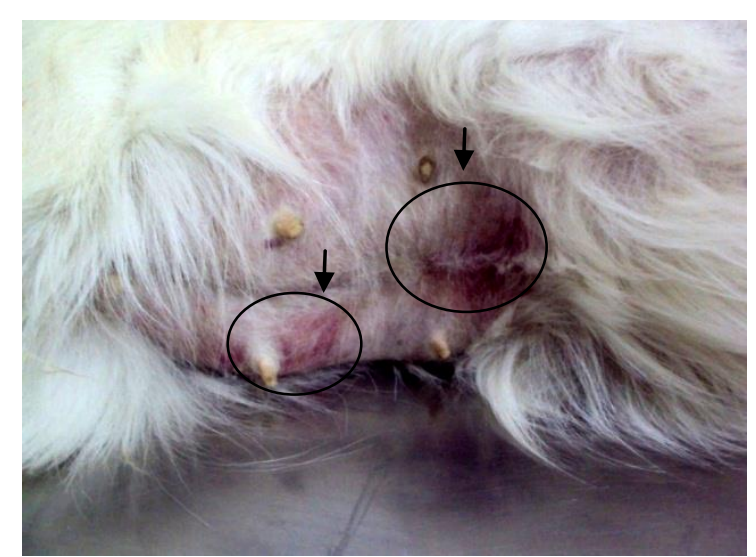

Figura 3. Imagem de cadela, SRD, com suspeita de MM. Presença de sufusões em região abdominal ventral (seta).

\section{DISCUSSÃO}

Os sinais clínicos apresentados por cães com MM são, muitas vezes, inespecíficos (Tripp et al., 2009). Outras condições patológicas podem caracterizar-se por sinais clínicos e laboratoriais semelhantes, tornando difícil o diagnóstico e retardando a instituição da terapêutica adequada. Umas dessas enfermidades é a erliquiose canina, que se caracteriza por febre, depressão, letargia, anorexia, esplenomegalia e tendências hemorrágicas (Harrus e Warner, 2011). A erliquiose é altamente prevalente na cidade de Salvador (Souza et al., 2010), onde se localiza o hospital veterinário responsável pelo atendimento. Fatores epidemiológicos devem ser levados em consideração no procedimento diagnóstico, o que determinou a primeira suspeita clínica do presente caso e o tratamento inicialmente instituído.
As apresentações clínicas de ambas as patologias, a erliquose e o MM, podem ser bastante semelhantes e incluem petéquias, equimoses e epistaxe (Sternberg et al., 2009; Harrus e Warner, 2011). Podem ainda ser observadas lesões oftalmológicas e neurológicas associadas a hemorragias intracranianas e intraoculares (Dispenzieri e Kyle, 2005). Na fase crônica da erliquiose, a trombocitopenia é geralmente grave e pode ser acompanhada por anemia acentuada e leucopenia (Sternberg et al., 2009). Pancitopenia acentuada devido à hipoplasia da medula óssea é outra característica da erliquiose crônica (Harrus e Warner, 2011). No presente relato, a cadela apresentava sinais clínicos (apatia, hiporexia, epistaxe, petéquias, sufusões) e laboratoriais (anemia, trombocitopenia, leucopenia, hiperglobulinemia) compatíveis com erliquiose, tendo sido essa, portanto, a primeira suspeita clínica. O animal apresentou uma resposta inicial positiva à terapêutica instituída. A recorrência do quadro clínico, cerca de 30 dias após a melhora inicial, levou à suspeita clínica de uma neoplasia hematológica.

Tanto em seres humanos como em cães, o diagnóstico do MM baseia-se na demonstração de pelo menos dois dos seguintes critérios: proliferação de células plasmáticas atípicas na medula óssea (>10\%), gamopatia monoclonal, lesões ósseas líticas e proteinúria de Bence-Jones (Tripp et al., 2009). No homem, algumas diretrizes mais recentes exigem a inclusão de um critério maior e outro menor (Geigy et al., 2012). Critérios maiores incluem plasmocitose de medula óssea acima de $30 \%$, caracterizando uma infiltração medular elevada, e elevação sérica de globulina monoclonal, detectada por meio de eletroforese $(>3,5 \mathrm{~g} / \mathrm{dL}$ para $\mathrm{IgG}$ ou $>2 \mathrm{~g} / \mathrm{dL}$ para 
IgA) (Faria e Silva, 2007). Critérios menores incluem plasmocitose de medula óssea entre $10 \mathrm{e}$ $30 \%$ (infiltrado moderado), lesões ósseas líticas e ocorrência de pico de globulina monoclonal, porém em proporções menores do que as estabelecidas no critério maior (Tripp et al., 2009; Geigy et al., 2012). A presença de infiltrado plasmocitário maior que $20 \%$, observada no mielograma do presente relato, conduziu ao diagnóstico de MM com base no critério menor. Além disso, foram observados dois picos monoclonais em beta e gamaglobulinas na eletroforese de proteínas séricas, atribuídos à secreção por células neoplásicas (Ruthanne Chun, 2005).

O aumento da viscosidade sanguínea que ocorre no $\mathrm{MM}$, secundário às elevadas concentrações de paraproteína circulante resulta na diminuição do aporte sanguíneo em órgãos e tecidos, por promover estase sanguínea em vasos de menor calibre. Cerca de um terço dos cães e gatos com MM tem sinais clínicos de sangramento, mais comumente epistaxe, hemorragia intraocular e sangramento gengival (Hanna, 2005). Sobrecarga cardíaca, insuficiência renal, retinopatias também são manifestações clínicas consequentes da síndrome da hiperviscosidade (Sternberg et al., 2009). Tanto a hiperviscosidade quanto a trombocitopenia apresentadas pela cadela descrita no presente relato podem acarretar diáteses hemorrágicas, justificando a presença de petéquias e sufusões na região abdominal no final do curso.

A hipercalcemia, que está relacionada ao aumento da atividade osteoclástica, induzida pelas células neoplásicas do MM, resultando em uma intensa reabsorção óssea, é outro achado comumente citado na literatura (Ruthanne Chun, 2005). Suas consequências clínicas incluem perda óssea difusa, lesões líticas e fraturas. Essas alterações ocorrem em cerca de 15 a $20 \%$ dos cães portadores do MM (Geigy et al., 2012) e corroboram os achados descritos no presente relato, em que foi ainda observado aumento do cálcio sérico corrigido, além de alterações radiográficas sugestivas de lesão lítica.

Além da trombocitopenia, a cadela aqui descrita apresentou anemia e leucopenia persistentes mesmo após tratamento. Essas alterações podem ser justificadas devido à ocupação do espaço medular por células neoplásicas, as quais liberam citocinas inflamatórias como o fator de necrose tumoral (TNF), que atuam inibindo a proliferação dos precursores eritrocitários e leucocitários (Weiss e Goodnough, 2005). Infecções secundárias, resultantes de imunossupressão, são consideradas causas importantes de morbidade, caracterizando-se uma das principais causas de mortalidade em pacientes com MM (Hanna, 2005).

As complicações neurológicas apresentadas por pacientes com MM podem ser decorrentes da compressão nervosa por fraturas, hipercalcemia, síndrome de hiperviscosidade, toxicicdade secundária ao tratamento. Essas complicações incluem neuropatias periféricas, radiculopatias espinhais, paralisia de nervos cranianos, compressão da medula espinhal e uma série de encefalopatias metabólicas (Dispenzieri e Kyle, 2005). O envolvimento de nervos cranianos e de suas ramificações consiste em complicações raras no $\mathrm{MM}$ e, quando ocorre, está associado à progressão da doença (Denier et al., 2006). A cadela do presente relato apresentava uma paralisia rígida da musculatura facial bilateral, com efeito de face de máscara, que, até onde esta revisão de literatura alcançou, ainda não foi descrita em MM em cães. A aparência facial da cadela aqui relatada, ainda, era semelhante à face paralisada verificada na síndrome de Moebius, que ocorre em seres humanos. Embora com uma fisiopatologia distinta, a síndrome de Moebius apresenta-se com ausência da mímica facial, caracterizando "a face de máscara", decorrente da paralisia do nervo facial (Diogo et al., 2009).

Assim, reporta-se o achado inédito e atípico de paralisia facial espástica bilateral em canino acometido por mieloma múltiplo. As evidências clínicas, laboratoriais e radiográficas conduziram ao diagnóstico de mieloma múltiplo, após suspeita clínica inicial de hemoparsitose. Dessa forma, apesar de ser uma neoplasia rara, o MM deve ser incluído no plano diagnóstico de doenças que acometem o sistema hemolinfático, mesmo em áreas endêmicas para infecções com sinais semelhantes. 


\section{REFERÊNCIAS}

DENIER, C.; LOZERON, P.; ADAMS, D. et al. Multifocal neuropathy due to plasma cell infiltration of peripheral nerves in multiple myeloma. Neurology, v.66, p.917-918, 2006.

DIOGO, F.S.F.; AGUIAR, S.M.H.C.A.; FARIA, C.C.M.; ROCHA, G.S.T. Utilização do misoprostol (Cytotec $®$ ) como droga abortiva e sua relação com a sídrome de moebius: relato de caso. Rev. Odontol. Araçatuba, v.30, p.31-35, 2009.

DISPENZIERI，A.; KYLE，R.A. Neurological aspects of multiple myeloma and related disorders. Best Pract. Res. Clin. Haematol., v.18, p.673-688, 2005.

FARIA, R.M.D.; SILVA, R.O.P. Gamatopatias monoclonais: critérios diagnósticos e diagnóstico diferencial. Rev. Bras. Hematol. Hemoter., v.29, p.17-22, 2007.

GEIGY, C.; RIOND, B.; BLEY, C.R. et al. Multiple myeloma in a dog with multiple concurrent infectious diseases and persistent polyclonal gammopathy. Vet. Clin. Pathol., v.42, p.47-54, 2013.

HANNA, F. Multiple myelomas in cats. J. Feline Med. Surg., v.7, p.275-287, 2005.
HARRUS, S.; WANER, T. Diagnosis of canine monocytotropic ehrlichiosis (Ehrlichia canis): an overview. Vet. J., v.187, p.292-296, 2011.

RUTHANNE CHUN, D.V.M. Common malignant musculoskeletal neoplasms of dogs and cats. Vet. Clin. Small Anim. Pract., v.35, p.1155-1167, 2005.

SOUZA, B.M.P.S.; LEAL, D.C.; BARBOZA, D.C.P.M. et al. Prevalence of ehrlichial infection among dogs and ticks in northeastern Brazil. Rev. Bras. Parasitol. Vet., v.19, p.89-93, 2010.

STERNBERG, R.; WYPIJ, J.; BARGER, A.M. An overview of multiple myeloma in dogs and cats: these plasma cell tumors originate in the bone marrow and can cause a variety of effects, from hemorrhaging to spinal cord compression. Vet. Med., p.468-476, 2009.

TRIPP, C.D.; BRYAN, J.N.; WILLS, T.B. Presumptive increase in protein-bound serum calcium in a dog with multiple myeloma. Vet. Clin. Pathol., v.38, p.87-90, 2009.

WEISS, G.; GOODNOUGH, L.T. Anemia of chronic disease. New Engl. J. Med., v.352, p.11-23, 2005. 